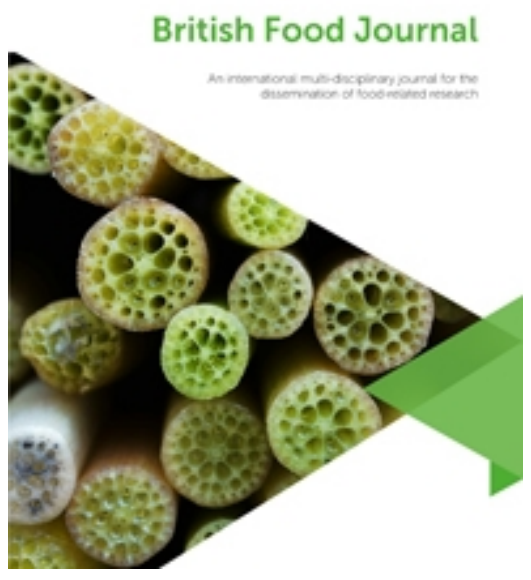

\title{
Burnout, Eating Behaviour Traits and Dietary Patterns
}

\begin{tabular}{|r|l|}
\hline Journal: & British Food Journal \\
\hline Manuscript ID & BFJ-04-2019-0300.R2 \\
\hline Manuscript Type: & Research Paper \\
\hline Keywords: & Burnout, Eating Traits, Food choice, Dietary patterns, Survey \\
\hline \multicolumn{2}{l}{} \\
\end{tabular}




\section{Burnout, Eating Behaviour Traits and Dietary Patterns}

\section{Abstract}

3 Purpose: This exploratory research investigated whether burnout and eating behaviour 4 traits were associated with food intake.

5 Design: Participants $(\mathrm{N}=109) 78 \%$ female, mean age 39 years, were recruited from

6 various occupations within a United Kingdom (UK) university to complete an on-line 7 survey. Dietary habits were measured using Food Frequency Questionnaire (FFQ),

8 burnout using the Maslach Burnout Inventory (MBI) and eating behaviour traits using 9 the Three Factor Eating Questionnaire R18 (TFEQ).

10 Findings: Principal Component Analyses of FFQ responses revealed four dietary 11 patterns: 1. Fast/Junk Food (+ chicken and low fruit/vegetables); 2. Meat/Fish; 3. 12 Dairy/Grains; 4. Beans/Nuts. Dietary patterns were examined using multiple regression 13 analysis as outcome variables with age, gender, burnout and eating behaviour traits as 14 explanatory variables. More frequent consumption of 'junk/fast food' was associated 15 with lower TFEQ-Cognitive Restraint, higher TFEQ-Uncontrolled Eating, lower MBI16 Emotional Exhaustion and higher MBI-Depersonalisation. More frequent consumption 17 of beans/nuts was associated with higher TFEQ-Uncontrolled Eating and higher MBI18 Emotional Exhaustion. Models for meat/fish and grains/dairy dietary patterns were not 19 significant.

20 Limitations/Implications: Burnout may need to be considered to reduce junk food 21 consumption in higher education employees. Causality between burnout, eating 22 behaviour traits and food consumption requires further investigation on larger samples. 
23 Originality: This appears the first study to have explored associations between burnout, 24 eating behaviour traits and dietary patterns.

25 Paper type: Research article.

26 Keywords: Burnout; Eating Traits; Food Choice; Dietary Patterns; Survey. 


\section{Burnout, Eating Behaviour Traits and Food Choice}

29

30

32

33

\section{Introduction}

Occupation-related factors contribute substantially to health and well-being (Shuck et al., 2017) and this is reflected in rising incidence of chronic illness among academics (Brown and Leigh, 2018). University staff experience relatively high workload demands (Ahsan et al., 2009) which may adversely affect job performance and produce burnout (Maslach and Leiter, 2014). Burnout is "a syndrome of emotional exhaustion, depersonalisation and reduced accomplishment which is a special risk for individuals who work with other people in some capacity" (Leiter and Maslach, 1998: pp 347). The Job Demand Resources Model (Demerouti et al., 2001) holds that greater effort is required to do a job where demands are high (eg. time constraints; role conflict; workload etc), leading to exhaustion and if resources are scarce, leading to disengagement. Occupational burnout occurs, therefore, when job demands exceed employees' resources for managing tasks (Schaufeli, 2017) and is common in occupations involving numerous direct interactions with people, such as those who work in education (Schaufeli and Salanova, 2014; Childs and Stoeber, 2012). Whereas resources are associated with greater commitment to the job and less burnout (Bakker et al., 2003), high job demands lead to burnout and associated detriment to health (Schaufeli, 2017). Recent meta-analysis (Lesener et al., 2018) has implied that the relationship between job demands or resources and burnout is reciprocal. Whist job demands lead to reduced work engagement, which increases job demands, resources improve well-being, which leads to further investment into work. Burnout may encourage less healthy eating behaviours (Alexandrova-Karamanova et al., 2016; 
51 Stewart-Knox, 2014; Gorter et al., 2000) and has been linked to overeating

52 (Mikalauskas et al., 2018; Armenta-Hernandez et al., 2018; Warren et al., 2013).

53

54

55

56

57

58

59

60

61

62

63

64

65

66

67

68

69

70

71

72

73

Eating behaviour traits can modulate food intake and could influence how individuals' eating patterns respond to burnout. Eating behaviour traits are individual differences assumed to be associated with appetite control (Drapeau et al., 2019). Disinhibition is an eating trait associated with poor appetite control characterized by 'Uncontrolled Eating' (UE) and Emotional Eating (EE). UE refers to the tendency to overeat in response to external food cues and food palatability while EE refers to the tendency to overeat in response to mood. Both EE and UE can be associated with weight gain (Bryant et al., 2008). Cognitive Restraint in contrast, is characterized by controlled eating, cognitively restricting food intake to control body weight (Bryant et al., 2008). Emotional Eating, Uncontrolled Eating and Cognitive Restraint are measured by the Three Factor Eating Questionnaire (Stunkard and Messick, 1985). Emotional states can increase food intake in restrained/emotional eaters and decrease in nonrestrained/non-emotional eaters (Kristanto et al., 2016; Aldao and Nolen-Hoeksema, 2010). One form of Disinhibition is Emotional Eating (EE) and is measured by the TFEQ revised TFEQr18 (Cappelleri et al., 2009; Karlsson et al., 2000). Individuals with a high level of Disinhibition (uncontrolled eating) and Restraint (controlled eating) may be vulnerable to overeating in response to negative emotion (Kozak et al., 2017; Järvelä-Reijonen et al., 2016; Bryant et al., 2010; and, 2008). Evidence for the impact of Cognitive Restraint on food intake, however, is mixed. On the one hand, Cognitive Restraint has been related to increased consumption of more healthful, and lower fat, low energy foods (e.g. Aguirre et al., 2017; Bernstein et al., 2015; French et al., 2014; 
74 Cornelis et al., 2014), supporting a behavioural profile which favours weight regulation.

75 Whilst on the other hand, high Cognitive Restraint has been associated with poorer diet 76 quality, poor dietary regulation and larger portion size (e.g. Guillocheau et al., 2018; 77 Lewis et al., 2015; Jones et al., 2013). The disparate response of those with high 78 Restraint, could at least in part, be a consequence of other eating behaviours an 79 individual processes, along with their emotional response (Bryant et al., in press). More 80

consistently, individuals who score highly on EE, show a tendency to consume high-fat and sweet foods (Järvelä-Reijonen et al., 2016; Camilleri et al., 2014). Emotional eaters, therefore, may be more likely to seek solace from food in the presence of burnout (Bond et al., 2001). In keeping with this theory, periods of high workloads have been associated with greater energy and fat intake (Wang and Le, 2015; Ng and Jeffery, 2003), particularly in people with high Disinhibition (Habhab et al., 2009; Wardle et al., 2000). Evidence for an association between burnout (MBI) and EE (TFEQr18) (Kristanto et al., 2016; Nevanperä et al., 2012) and uncontrolled eating (Nevanperä et al., 2012), suggests Disinhibition and Cognitive Restraint could be important when explaining eating patterns under conditions of burnout.

Research on burnout and health has mainly focussed upon health professionals (Mikalauskas et al., 2018; Alexandrova-Karamanova et al., 2016; Cecil et al., 2014; Warren et al., 2013; Gorter et al., 2000). Most existing studies on burnout and eating have not assessed actual dietary habits and/or dietary patterns (eg. Mikalauskas et al., 2018; Kristanto et al., 2016; Nevanpera et al., 2012; Gorter et al., 2000). This exploratory study, therefore, has explored associations between burnout, eating traits and dietary patterns in employees within higher education with a view to intervention. It 
97 was hypothesized that burnout, emotional eating, uncontrolled eating and Cognitive 98 Restraint would be associated with eating patterns.

100 Method

101 Sampling

102 Recruitment was via email and newsletter from among University employee groups 103 (academic; administrative; ancillary) and all grades. Those with a dietary-related health 104 condition (eg. Diabetes; Coeliac's disease; food allergy) or on a prescribed diet (eg. low 105 cholesterol; gluten free) were excluded. Otherwise any employee was free to volunteer 106 and be included. Respondents $(\mathrm{N}=109)$ were $78 \%$ female, average age 39.50 years, $79 \%$ 107 of whom had a degree and/or higher degree. A majority (64.5\%) were in administrative 108 roles, one third (34\%) held academic posts and a small proportion (1.5\%) unclassified.

110 Materials

111 The design was cross-sectional using self-administered questionnaire. Questions were 112 on demographics, Perceived Stress, Emotion Regulation, Burnout, Eating Behaviour 113 Traits and dietary habits. Emotion Regulation data were omitted as incomplete. 114 Perceived Stress was removed from this analysis because of its low Cronbach's alpha 115 (0.547).

The Maslach Burnout Inventory (MBI) (Maslach and Leiter, 2014; Maslach and 117 Jackson, 1986) is a 22-item scale that assesses burnout on three subscales: 1) Emotional 
exhaustion (EE) (9 items) - feelings of being emotionally overextended and exhausted by work eg. 'I feel emotionally drained/used up/fatigued at the end of the day'; 2) Depersonalisation (DP) (5 items) - an unfeeling and impersonal response toward recipients of services eg. 'I can easily understand how my recipients feel about things/I feel I treat some recipients as if they were impersonal objects'/'working with people all day is a strain for me'; 3) Personal accomplishment (PA) (8 items) competence and achievement in one's work eg. 'I feel I am positively influencing other people's lives through my work'/'I feel exhilarated after working closely with my recipients'/'I have accomplished many worthwhile things in this job'. Responses were on a 7-point Likert scale ranging from "never" $(=0)$ to "daily" $(=6)$. Scores, one for each subscale, were entered separately into analyses as independent variables. The MBI has been shown to have good validity across different studies (Lesener et al., 2019) and high internal consistency for the EE and DP scales across EU countries (Alexandrova-Karamanova et al., 2016). Internal consistency of the reported data was high. Cronbach's $\alpha=0.91$ (EE); 0.78 (DP); 0.83 (PA).

Three Factor Eating Questionnaire Revised 18 (TFEQr18) (Karlsson, et al., 134 2000) measures eating traits and is a shortened and revised version of the 51-item 135 original (Stunkard and Messick, 1985).. Responses were on a four-point scale (1-4), 136 with higher values indicating greater levels of the eating behaviour trait. Item scores 137 were summated into scale scores for three factors: "Cognitive Restraint" (CR) 6 items; 138 "Uncontrolled Eating" (UE) 9 items; "Emotional Eating" (EE) 3 items. Raw scores were 139 transformed to a $0-100$ scale [(lowest possible raw score/possible raw score range) $\mathrm{x}$ 140 100]. Scores, one for each subscale, were entered separately into the analyses as 
141 independent variables. Internal consistency of the subscales was good. Cronbach's $\alpha=$ $1420.83(\mathrm{CR}) ; 0.89(\mathrm{UE}) ; 0.89(\mathrm{EE})$.

Food Frequency Questionnaire (FFQ) (Adapted from Tresserra-Rimbau, et al.,

144 2013) was employed to measure how often 19 food groups (Table 1) were consumed 145 during the previous three months. Responses were on a Likert scale: never; less than 1 146 time per week; 1-6 times per week; 1-3 times per day; 4 or more times per day.

\section{Procedure}

149 Ethical approval was granted by the University ethical committee. Volunteers were 150 given an information sheet and required to give prior, written consent. Data were 151 collected on-line during April-August 2015.

153 Data analysis

154 Data were analysed using Jamovi (version 0.9.5.12) and R (version 3.5.1). Principal 155 Component Analysis (PCA) with Varimax rotation using R library "psych" (Revelle, 156 2018) was used to determine dietary patterns from FFQ data. Taking factor loadings of 1570.5 or above and Eigenvalues $>1$, initial results indicated 6 components. Given two 158 components that explained the least variances were not interpretable, the PCA was re159 run assuming 4 components which together accounted for $55.7 \%$ of the total variance 160 in frequency of consumption. Taking factor loadings of 0.5 as cut-off, there were 4 161 factors (Table 1), each representing a distinct dietary pattern: 1. Junk/Fast Food + 
162 Chicken and Low Fruit/Vegetables; 2. Meat/Fish; 3. Grains/Dairy; 4. Beans/Nuts.

163 Neither eggs nor sweets loaded onto any factor. The 4 component scores (dietary 164 patterns) were entered into multiple regression analyses as dependent variables.

165 Multiple linear regression analyses were then undertaken to determine associations 166 between gender, age, burnout (MBI) and eating behaviour traits (TFEQ) (independent 167 variables) and the four dietary patterns dependent variables). Significance was assumed 168 at $\mathrm{p}<0.05$. See Table 2 for the descriptive statistics of the independent variables.

169 For all four models, the assumptions of linearity, homoscedasticity, and 170 normality were acceptable based on results of normal Q-Q plots, residual plots, the 171 score test for non-constant error variance (Cook and Weisberg, 1983), and the global 172 validation of linear model assumption test (Peña and Slate, 2006). Independence was 173 assumed by design. Results of VIF indicated no problem of multicollinearity $(<10)$.

174 Outliers and influential cases were examined using Cook's distance, hat statistic, added175 variable plots, and influence plots. Although there were outliers based on Cook's 176 distance, these data points were included in the analyses because the largest absolute 177 studentised residual test showed that these outliers were not significant using the 178 Bonferroni $p<.05$ criterion. The added-variable plots and influence plots indicated 179 these outliers did not have a disproportionate impact on the model parameters.

$181 \quad$ Insert Table 1 and 2 
184

185

186

187

188

189

190

191

192

193

194

195

196

197

198

199

200

201

202

203

204

205

\section{Determinants of dietary patterns}

\section{Fast/Junk Food}

More frequent consumption of the 'junk/fast food' (+ chicken and less-frequent fruit and veg) pattern was associated with lower TFEQ-Restrained Eating $(b=-0.012 ; S E=$ 0.004; $t=-2.975 ; p=0.004)$, higher TFEQ-Uncontrolled Eating $(b=0.014 ; S E=0.005$; $t=2.656 ; p=0.010)$, lower MBI-Exhaustion $(b=-0.024 ; S E=0.010 ; t=-2.516 ; p=$ $0.014)$ and higher MBI-Depersonalisation $(b=0.049 ; S E=0.020 ; t=2.437 ; p=0.017)$ (Table 3). This model explained $44.1 \%$ of variance (adjusted $\mathrm{R}^{2}=0.38$ ) in junk/fast food consumption $(F(8,77)=7.597 ; S E=0.80, p<0.001)$.

2. Meat/Fish

More frequent consumption of the meat/fish dietary pattern was associated with being male $(b=-0.665 ; S E=0.269 ; t=-2.475 ; p=0.016)$ (Table 3$)$. This model explained $11 \%$ of variance (adjusted $\left.\mathrm{R}^{2}=0.03\right)$ in meat consumption and was not significant $(F$ $(8,77)=1.28 ; S E=0.964 ; p=0.266)$.

\section{Grains/Dairy}

More frequent consumption of the grains/dairy dietary pattern was associated with being male $(b=-0.671 ; S E=0.272 ; t=-2.468 ; p=0.016)$ (Table 3$)$. This model explained $9 \%$ of variance (adjusted $\mathrm{R}^{2}=-0.001$ ) in grains and dairy consumption and was not significant $(F(8,77)=0.987 ; S E=0.974 ; p=0.453)$.

\section{Beans/Nuts}

More frequent consumption of beans/nuts was associated with higher TFEQUncontrolled Eating $(b=0.015 ; S E=0.006 ; t=2.463 ; p=0.016)$ and higher MB- 
206 Exhaustion $(b=0.027 ; S E=0.011 ; t=2.460 ; p=0.016)$ (Table 3$)$. This model was 207 significant and predicted $22 \%$ of the variance (adjusted $\mathrm{R}^{2}=0.14$ ) in the frequency of 208 bean and nut consumption $(F(8,77)=2.697 ; S E=0.916 ; p=0.011)$.

Further analyses examined the Fast/Junk Food and Beans/Nuts dietary pattern 210 models that indicated overall significance for relative importance of the significant 211 predictors using relative weights (Groemping, 2006). Relative weight estimates the 212 contribution each predictor makes to $\mathrm{R}^{2}$. For the Fast/Junk Food model, TFEQ213 Uncontrolled Eating had the highest relative weight (27.44\%), followed by TFEQ214 Cognitive Restraint (23.41\%), MBI-Depersonalisation (15.24\%), and MBI-Exhaustion 215 (6.02\%). For the Beans/Nuts model, TFEQ-Uncontrolled Eating again had the highest 216 relative weight (31.94\%), followed by MB-Exhaustion (29.31\%).

\section{Insert Table 3}

\section{Discussion}

221 As predicted, given previous research which has identified associations between 222 burnout and less healthy eating (Alexandrova-Karamanova et al., 2016; Lallukka et al., 223 2008; Gorter et al., 2000) burnout (depersonalisation) was associated with more 224 frequent fast/junk (+ chicken and less-frequent fruit and veg) food consumption. 225 Contrary to expectation, more frequent consumption of fast food was associated with 226 less burnout (exhaustion). This variable explained a relatively small proportion (6\%) of 227 the model. A possible explanation for this finding is that the relationship between 
228 burnout (exhaustion) and fast-food intake is circular. Exhaustion leads to fast-food 229 consumption which serves to counter exhaustion and in doing so, reinforces further 230 intake of fast-food and so on. Contrary to previous research which has found that males 231 consume more fast-food than females (Daniuseviciute-Brazaite and Abromaitiene, 232 2018; Jansen et al., 2017; Saquib et al., 2016; Black and Billette, 2015; Morse and 233 Driskell, 2009), our data showed no sex differences in the fast food intake pattern. That 234 our sample was $78 \%$ female, however, may have rendered this null finding less reliable. Frequent 'junk/fast food' (+ chicken and less-frequent fruit and veg) 236 consumption pattern was strongly associated with lower restrained eating and higher 237 uncontrolled eating. This finding agrees with previous studies that have linked 238 emotional eating to with job stress (Okumus et al., 2019) or uncontrolled eating to 239 intake of high-energy-containing foods (Camilleri et al., 2014) and implies that such 240 individuals may be less able to change eating behaviour. The result, however, 241 contradicts other studies that have found no association between eating traits and food 242 intake (Brogan and Hevey, 2013; Adriaanse et al., 2011; Anschutz et al., 2009) 243 suggesting that further research is required.

That more frequent consumption of beans/nuts was also associated with higher 245 uncontrolled eating in the presence of burnout (exhaustion), suggests that some 246 uncontrolled eaters target urges at healthier food, which could be a result of individual 247 differences that moderate the relationship between burnout and eating and could explain 248 inconsistencies in results between studies. Uncontrolled eaters may eat more regardless 249 of healthiness. There may have been an interaction amongst eating behaviour traits, 250 whereby level of Cognitive Restraint may have affected the expression of Uncontrolled 
251 Eating (Bryant et al., 2010). Where there is high Uncontrolled Eating with high 252 Cognitive Restraint, a more disturbed eating style can develop with overeating of less 253 healthy foods. Those with low Cognitive Restraint and high Uncontrolled Eating, 254 however, may overeat all food, healthy or otherwise.

Among limitations inherent in this study is that the workplace context may have 256 rendered work-related matters salient and biased responses toward burnout (Schaufeli et al., 2009). The sample, although adequate for an exploratory study, was small and biased toward females. Although all are contracted to a 37-hour working week, academics can work longer. Future research on larger and more representative samples, therefore, should be conducted in order for findings to be generalised to other higher education employees. Future research may compare burnout and food intake between academics and administrative staff and different job roles as well as between full and part-time workers and taking the wider context into account.

The FFQ will have contained inaccuracies common to any self-reported, recall 265 approach to dietary assessment (MacDiarmid and Blundell, 1998). The FFQ used in the current study did not distinguish between fresh and processed foods which would have strengthened extraction of the dietary patterns. Given previous studies have reported overeating in response to burnout (Armenta-Hernandez et al., 2018; Mikalauskas et al.,

269 2018; Warren et al., 2013), it would have been useful to have assessed portion size and 270 included anthropometric measures. That the FFQ covered a reference period of three 271 months, rendered it difficult to assess portion size, however, this is not a problem given 272 the focus of the current study was on dietary quality not quantity. A strength of the 273 current analysis is that unlike previous studies of burnout and eating (Okumus et al., 
274 2019; Alexandrova-Karamanova et al., 2016; Kristanto et al., 2016; Nevanpera et al., 275 2012), the present study measured intake and has analysed dietary patterns.

Another omission given previous research which has found associations between

277 burnout and higher alcohol intake (Mikalauskas et al., 2018; Alexandrova-Karamanova 278 et al., 2016; Cecil et al., 2016; Gorter et al., 2000; Nowack and Pentkowski, 1994), is 279 that the questionnaire did not enquire of alcohol intake. Assessment of physical activity 280 may also have strengthened the models.

Like much research into occupational wellbeing (Lesener et al., 2019), our study 282 has been cross-sectional, meaning further research on larger samples comprising a range 283 of job roles is required to ascertain direction of causation between burnout, eating traits 284 and food choice. Meanwhile, these results suggest that different types of burnout 285 (Emotional Exhaustion and Depersonalisation) and eating behaviour traits 286 (Uncontrolled Eating and Cognitive Restraint) are differentially associated with 287 junk/fast food consumption. These results have implications on workplace wellbeing 288 interventions to promote healthier food choices.

\section{References}

291 Adriaanse, M.A. de Ridder, D.T. and Evers, C. (2011), Emotional eating: Eating when 292 emotional or emotional about eating? Psychology and Health, Vol 26, pp. 23-39.

293 Aguirre, T.M. Kuster, J.T. and Koehler, A.E. (2017), Relationship between eating 294 behavior and dietary intake in rural Mexican-American mothers. Journal of Immigrant 295 and Minority Health Vol 19, pp. 225-7. doi:10.1007/s10903-015-0324-8. 
296 Ahsan, N. Abdullah, Z. Fie, D.G. and Alam, S.S. (2009), A study of job stress on job 297 satisfaction among university staff in Malaysia: Empirical study. European Journal of 298 Social Sciences, Vol 8, pp.121-131.

299 Aldao, A. and Nolen-Hoeksema, S. (2010), Specificity of cognitive emotion regulation 300 strategies: A transdiagnostic examination. Behaviour Research and Therapy, Vol 48, 301 pp. 974-983.

302 Alexandrova-Karamanova, A. Todorova, I. Montgomery, A. Panagopoulpou, E. Costa, 303 P. Baban A. Davas, A. Milsovic, M. and Mijakoski, D. (2016), Burnout and health 304 behaviors in health professionals from seven European countries. International Archives 305 of Occupational and Environmental Health, Vol 89, pp. 1059-1075.

306 Anschutz, D.J. Van Strien, T. Van De Ven, M.O. and Engels, R.C. (2009)., Eating 307 styles and energy intake in young women. Appetite, Vol 53, pp. 119-122.

308 Armenta-Hernandez, O.D. Maldonado-Macias, A. Garcia-Alcaraz, J. Avelar-Sosa, L. 309 Ralyvasquez-Vargas, A. and Serrano-Rosa, M.A. (2018), Relationship between burnout 310 and body mass index in senior and middle managers from the Mexican manufacturing 311 industry. International Journal of Environmental Research and Public Health, Vol 15, 312 pp. 541.

313 Bakker, A.B. Demerouti, E. de Boer, E. and Schaufeli, W.B. (2003), Job demands and 314 job resources as predictors of absence duration and frequency. Journal of Vocational 315 Behavior, Vol 62, pp. 341-356. 
316 Bernstein, E.E. Nierenberg, A.A. Deckersbach, T. and Sylvia, L.G. (2015), Eating 317 behavior and obesity in bipolar disorder. Australia and New Zealand Journal of 318 Psychiatry, Vol 49,pp. 566-72. doi:10.1177/0004867414565479.

319 Black, J.L. and Billette, J.M. (2015), Fast food intake in Canada: Differences among 320 Canadians with diverse demographic, socio-economic and lifestyle characteristics. 321 Canadian Journal of Public Health, Vol 106, pp. E52-58.

322 Bond, M.J. McDowell, A.J. and Wilkinson, J.Y. (2001), The measurement of dietary 323 restraint, disinhibition and hunger: an examination of the factor structure of the Three 324 Factor Eating Questionnaire (TFEQ). International Journal of Obesity, Vol 25, pp. 900325906.

326 Brogan, A. and Hevey, D. (2013), Eating styles in the morbidly obese: restrained eating, 327 but not emotional and external eating, predicts dietary behaviour. Psychology and 328 Health, Vol 28, pp. 714-725.

329 Brown, N. and Leigh, J. (2018), Ableism in academia: where are the disabled and ill 330 academics? Disability and Society, Vol 33, pp. 985-989.

331 Bryant, E.J. King, N.A. and Blundell, J.E. (2008), Disinhibition: its effects on appetite 332 and weight regulation. Obesity Reviews, Vol 9, pp. 409-419.

333 Bryant, E.J. Kiezebrink, K. King, N.A. and Blundell, J.E. (2010), Interaction between 334 disinhibition and restraint: Implications for body weight and eating disturbance. Eating 335 and Weight Disorders, Vol 15, pp. e43-e51. 
336 Bryant, E.J. Rehman, J., Pepper, L.B. and Waters, E.R. (in press), Obesity and eating 337 disturbance: The role of Restraint and Disinhibition. Current Obesity Reports, .

338 Camilleri, G.M. Méjean, C. Kesse-Guyot, E. Andreeva, V.A. Bellisle, F. Hercberg, S. and Péneau, S. (2014), The associations between emotional eating and consumption of 340 energy-dense snack foods are modified by sex and depressive symptomatology. Journal 341 of Nutrition, jn-114.

342 Cappelleri, J.C. Bushmakin, A.G. Gerber, R.A. Leidy, N.K. Sexton, C.C. Lowe, M.R.

343 Karlson, J. (2009), Psychometric analysis of the Three-Factor Eating Questionnaire344 R21: results from a large diverse sample of obese and non-obese participants. 345 International Journal of Obesity, Vol 33, pp. 611-20.

346 Cecil, J. McHale, C. Hart, J. and Laidlow, A. (2014), Behaviour and burnout in medical 347 students. Medical Education Online, Vol 19, pp. 25209.

348 Childs, J.H., and Stoeber, J. (2012). Do you want me to be perfect? Two longitudinal 349 studies on socially prescribed perfectionism, stress and burnout in the workplace. Work 350 and Stress, Vol 26, pp.347-364.

351 Cook, R. D., and Weisberg, S. (1983), Diagnostics for heteroscedasticity in regression. 352 Biometrika, Vol 70, 1-10. doi:10.2307/2335938

353 Cornelis, M.C. Rimm, E.B. Curhan, G.C. Kraft, P. Hunter, D.J. Hu, F.B. and van Dam, 354 R.M.(2014), Obesity susceptibility loci and uncontrolled eating, emotional eating and 355 cognitive restraint behaviors in men and women. Obesity, Vol 22, pp. E135-41. 356 doi:10.1002/oby.20592. 
357 Daniuseviciute-Brazaite, L. and Abromaitiene, L. (2018), Evaluation of student's 358 dietary behaviours depending on gender. Progress in Nutrition, Vol 20, pp. 21-29.

359 Demerouti, E. Nachreiner, F. Bakker, A.B. and Scaufeli, W.B. (2001), The job 360 demands-resources model of burnout. Journal of Applied Psychology, Vol 86, pp. 499361512.

362 Drapeau, V., Jacob, R., Panahi, S., and Tremblay, A. (2019), Effect of energy restriction 363 on eating behavior traits and psychobehavioral factors in the low satiety phenotype. 364 Nutrients, Vol 11, 1-14. doi:10.3390/nu11020245

365 French, S.A. Mitchell, N.R. Finlayson, G. Blundell, J.E. and Jeffery, R.W. (2014), 366 Questionnaire and laboratory measures of eating behavior. Associations with energy 367 intake and BMI in a community sample of working adults. Appetite, Vol 72, pp.50-8. 368 doi:https://doi.org/10.1016/j.appet.2013.09.020.

369 Gorter, R.C Eijkman, M.A. and Hoogstraten, J. (2000), Burnout and health among 370 Dutch dentists. European Journal of Oral Sciences, 108, 261-267.

371 Groemping, U. (2006), Relative Importance for Linear Regression in R: The Package 372 relaimpo. Journal of Statistical Software, 17, 1 - 27.

373 doi:http://dx.doi.org/10.18637/jss.v017.i01

374 Guillocheau, E. Davidenko, O. Marsset-Baglieri, A. Darcel, N. Gaudichon, C. Tomé, D. 375 Fromentin, G. (2018) Expected satiation alone does not predict actual intake of desserts. 376 Appetite, Vol 123, pp.183-90. doi:https://doi.org/10.1016/j.appet.2017.12.022. 
377 Habhab, S. Sheldon, J.P. and Loeb, R.C. (2009), The relationship between stress, 378 dietary restraint, and food preferences in women. Appetite, Vol 52, pp. 437-444.

379 Järvelä-Reijonen, E. Karhunen, L. Sairanen, E. Rantala, S. Laitinen, J. Puttonen, S.

380 Peuhkuri, K. Hallikainen, M. Juvonen, K. Myllymaki, T. Fohr, T. Pihlajamaki, 381 J. Korpela, R. Ermes, M. Lappalainen, R. and Kolehmainen, M. (2016), High perceived 382 stress is associated with unfavorable eating behavior in overweight and obese Finns of 383 working age. Appetite, Vol 103, pp. 249-258.

384 Jansen, H.G. Davies, I.G. Richardson, L.D. and Stevenson, L. (2017), Determinants of 385 take away and fast food consumption: a narrative review. Nutrition Research Reviews, 386 doi: 10.1017/S0954422417000178.

387 Jones, M.D. and Crowther, J.H. (2013), Predicting the onset of inappropriate 388 compensatory behaviors in undergraduate college women. Eating Behavior, Vol 14, pp. 389 17-20. doi:10.1016/j.eatbeh.2012.10.009.

390 Karlsson, J. Persson, L.O. Sjöström, L. and Sullivan, M. (2000), Psychometric 391 properties and factor structure of the Three-Factor Eating Questionnaire (TFEQ) in 392 obese men and women. Results from the Swedish Obese Subjects (SOS) study. 393 International Journal of Obesity, Vol 24, pp. 1715-1725.

394 Kristanto, T. Chen, W.S. Thoo, Y.Y. (2016), Academic burnout and eating disorder 395 among students in Monash University Malaysia. Eating Behaviors Vol 22, pp. 96-100.

396 Lallukka, T. Lahelma, E. Rahkonen, O. Roos, E. Laaksonen, E. Martikainen, P. and 397 Sekine, M. (2008), Associations of job strain and working overtime with adverse health 
398 behaviors and obesity: evidence from the Whitehall II Study, Helsinki Health Study, 399 and the Japanese Civil Servants Study. Social Science and Medicine, Vol 66, pp. 16814001698.

401 Leiter, M.P. and Maslach, C. (1998), Burnout. In SeiFriedman H. (Ed.), Encyclopedia 402 of Mental Health, Academic Press, New York pp. 347-357.

403 Lesener, T. Gusy B. and Wolter, C. (2019), The job-demands resources model: A meta404 analytic review of longitudinal studies. Work and Stress, Vol 33, pp. 76-103.

405 Lewis, H.B. Forwood, S.E. Ahern, A.L. Verlaers, K. Robinson, E. Higgs, S. Jebb, S.A. 406 (2015) Personal and social norms for food portion sizes in lean and obese adults. 407 International Journal of Obesity, Vol 39, pp. 1319-24. doi:10.1038/ijo.2015.47.

408 MacDiarmid, J. and Blundell, J. (1998), Assessing dietary intake: who, what and why of 409 under-reporting. Nutrition Research Reviews, Vol 11, pp. 231-253.

410 Maslach, C. Jackson, S.E. and Leiter, M.P. (1986), Maslach Burnout Inventory. Third 411 Edition, Consult. Psychol. Press, Palo Alto, CA.

412 Maslach, C. and Leiter, M.P. (2014), Burnout in the workplace. Psychology Serving 413 Humanity: Proceedings of the 30th International Congress of Psychology. Western 414 Psychology, Vol 2, pp. 116.

415 Mikalauskas, A. Benetis, R. Sirvinskas, E. Andrejaitiene, J. Kinduris, S. Macas, A. 416 Padaiga, Z. (2018), Burnout among anesthetists and intensive care physicians. Open 417 Medicine, Vol 13, pp. 105-112. 
418 Morse, K.L. and Driskell, J.A. (2009), Observed sex differences in fast-food 419 consumption and nutrition self-assessments and beliefs of college students. Nutrition 420 Research, Vol 29, pp. 173-179.

421 Nevanperä, N.J. Hopsu, L. Kuosma, E. Ukkola, O. Uitti, J. and Laitinen, J.H. (2012), 422 Occupational burnout, eating behavior, and weight among working women. The 423 American Journal of Clinical Nutrition, Vol 95, pp. 934-943.

424 Ng, D.M. and Jeffery, R.W. (2003), Relationships between perceived stress and health 425 behaviors in a sample of working adults. Health Psychology, Vol 22, pp. 638.

426 Nowack, K.M. and Pentkowski, A.M. (1994), Lifestyle habits, substance use and 427 predictors of job burnout in professional working women. Work and Stress, 8, 19-35.

428 Okumus, B. Chaulagain, S. and Giritlioglu, I. (2019), Examining the impacts of job 429 stress and job satisfaction on hotel employees' eating behavior. Journal of Hospitality 430 Marketing and Management, Vol 28, pp. 558-575.

431 Peña, E. A., and Slate, E. H. (2006), Global validation of linear model assumptions. 432 Journal of the American Statistical Association, Vol 101, 341-354.

433 Revelle, W. (2018), Procedures for Personality and Psychological Research. 434 Northwestern University, Evanston, Illinois, USA, https://CRAN.R435 project.org $/$ package $=$ psych Version $=1.8 .12$.

436 Saquib, J. Saquib, N. Stafanick, M.L. Khanam, M.A. Anand, S. Rahman, M. Chertow 437 G.M. Barry, M. Ahmed, T. and Cullen, M.R. (2016), Sex differences in obesity, dietary 
438 habits and physical activity among urban middle-class Bangladeshis. International 439 Journal of Health Sciences, Vol 10, pp. 363-372.

440 Schaufeli, W.B. (2017), Applying the job demands-resources model. Organizational 441 Dynamics, Vol 46, pp. 120-132.

442 Schaufeli, W.B. Leiter, M.P. and Maslach, C. (2009), Burnout: 35 years of research and 443 practice. Career Development International, Vol 14, pp. 204-220

444 Schaufeli, W.B. Bakker, A.B. Hoogduin, K. Schaap, C. and Kladler, A. (2001), On the 445 clinical validity of the Maslach Burnout Inventory and the Burnout Measure. 446 Psychology and Health, Vol 16, pp. 565-582.

447 Schaufeli, W.B. and Salanova, M.A.R.I.S.A. (2014), Burnout, boredom and engagement 448 at the workplace. In M.C.W. Peeters, J. de Jonge and T.W. Taris (Eds), An Introduction 449 to Contemporary Work Psychology First Edition (pp.293-320). Chichester, UK: John 450 Wiley and Sons.

451 Shuck, B. Alagaraja, M. Rose, K. Owen, J. Osam, K. and Bergman, M. (2017), The 452 health-related upside of employee engagement: exploratory evidence and implications 453 for theory and practice. Performance Improvement Quarterly, Vol 38, pp. 165-178.

454 Stewart-Knox, B.J. (2014), Eating and stress at work: the need for public health 455 promotion intervention and an opportunity for food product development. Trends in 456 Food Science and Technology, Vol 35, pp. 52-60.

457 Tresserra-Rimbau, A. Medina-Remón, A. Pérez-Jiménez, J. Martínez-González, M. A. 458 Covas, M.I. Corella, D. Salas-Salvado, J. Gomez-Gracia, E. Lapetra, J. Aros, F. Fiol, M. 
459 Ros, E. Serra-Majem, L. Pinto, X. Munoz, M.A. Saez, G.T. Ruiz-Gutierrez, V. 460 Warnberg, J. Estruch, R. and Lamuela-Raventos, R.M. (2013), Dietary intake and 461 major food sources of polyphenols in a Spanish population at high cardiovascular risk: 462 the PREDIMED study. Nutrition, Metabolism and Cardiovascular Diseases, Vol 23, 463 pp. 953-959.

464 Stunkard, A.J. and Messick, S. (1985), The three-factor eating questionnaire to measure 465 dietary restraint, disinhibition and hunger. Journal of Psychosomatic Research, Vol 29, 466 pp. 71-83.

467 Wang, E.S.T. and Li, Y.L. (2015), The effect of stress and visible health problems on 468 the intent to continue health food consumption. British Food Journal, Vol 117, pp. 302469317.

470 Wardle, J. Steptoe, A. Oliver, G. and Lipsey, Z. (2000), Stress, dietary restraint and 471 food intake. Journal of Psychosomatic Research, Vol 48, pp. 195-202.

472 Warren, C.S. Schafer, K.J. Crowley, M.E.J. and Olovardia, R. (2013), Demographic and 473 work-related correlates of job burnout in professional eating disorder treatment 474 providers. Psychotherapy, Vol 50, pp. 553-564. 
1 Table 1.

2 Component Loadings for Principle Components Analysis for Dietary Patterns with

3 Varimax Rotation

4

\begin{tabular}{|c|c|c|c|c|}
\hline \multirow[b]{2}{*}{ FFQ } & \multicolumn{4}{|c|}{ Components } \\
\hline & 1. Junk/Fast food & 2. Meat/Fish & 3. Grains/Dairy & 4. Beans/Nuts \\
\hline Dairy & .04 & .03 & .62 & .00 \\
\hline Fruit & -.58 & -.15 & .11 & .30 \\
\hline Chicken & .56 & .41 & .07 & -.07 \\
\hline F/Veg & -.76 & -.03 & .10 & .25 \\
\hline Legumes & -.63 & .17 & .20 & .17 \\
\hline Beans & -.16 & .22 & .14 & .65 \\
\hline Nuts & -.05 & .11 & -.13 & .72 \\
\hline Fish & .04 & .74 & .13 & .17 \\
\hline Pork & -.01 & .80 & .06 & .02 \\
\hline Beef & .12 & .83 & .13 & .09 \\
\hline Other Meat & .17 & .72 & .07 & .04 \\
\hline Grains & -.05 & .09 & .76 & .21 \\
\hline Eggs & .30 & .33 & .48 & .29 \\
\hline Bread & .26 & .09 & .71 & -.05 \\
\hline Sweets & .48 & -.21 & .31 & .43 \\
\hline Snacks & .67 & -.02 & .31 & .20 \\
\hline Soft Drinks & .54 & .19 & .16 & .07 \\
\hline Coffee/Tea & -.31 & .19 & .68 & -.16 \\
\hline Fast/Food & .63 & .36 & .11 & .17 \\
\hline
\end{tabular}

$5 \quad$ Note. $N=109$. Loadings $>|.50|$ are in boldface. FFQ $=$ Food Frequency Questionnaire.

$6 \quad$ F/Veg $=$ Fruit/Vegetables. 
Table 2.

Summary of Intercorrelations, Means, and Standard Deviations for Scores on Burnout and Eating Behaviour Traits

\begin{tabular}{|c|c|c|c|c|c|c|c|c|}
\hline & 1 & 2 & 3 & 4 & 5 & 6 & $M$ & $S D$ \\
\hline 1. Emotional Exhaustion & -- & $.59 * * *$ & -.14 & .01 & $.28 * *$ & $.30 * *$ & 19.9 & 11.8 \\
\hline Depersonalisation & & -- & -.18 & -.06 & $.36 * * *$ & .14 & 6.5 & 6.2 \\
\hline Personal Accomplishment & & & -- & -.10 & .03 & -.06 & 32.7 & 9.2 \\
\hline 4. Cognitive Restraint & & & & -- & -.03 & $.25^{*}$ & 41.8 & 23.0 \\
\hline 5. Uncontrolled Eating & & & & & -- & $.48 * * *$ & 37.7 & 22.0 \\
\hline 6. Emotional Eating & & & & & & -- & 36.4 & 28.7 \\
\hline
\end{tabular}

Note. $N=109 .{ }^{*} p<.5 . * * p<.01 . * * * p<.001$. 
$1 \quad$ Table 3.

2 Multiple Regression Analyses: Associations between Gender, Age, Burnout (MBI),

3 Eating Traits, and Dietary Pattern

4

\begin{tabular}{|c|c|c|c|c|}
\hline \multirow[b]{3}{*}{ Variables } & \multicolumn{4}{|c|}{ Dietary patterns } \\
\hline & Junk/Fast food & Meat/Fish & Dairy/Grains & Beans/Nuts \\
\hline & $B$ & $B$ & $B$ & $B$ \\
\hline Intercept & .813 & -.320 & .202 & $-1.403 *$ \\
\hline Age & -.001 & .009 & .003 & .006 \\
\hline Gender & -.381 & $-.665^{*}$ & $-.671^{*}$ & -.443 \\
\hline MBI-EE & $-.024 *$ & .009 & .004 & $.027 *$ \\
\hline MBI-DP & $.049 *$ & -.011 & -.024 & -.032 \\
\hline MBI-PA & -.001 & .015 & .002 & .013 \\
\hline TFEQ-CR & $-.012 * *$ & -.002 & .005 & .005 \\
\hline TFEQ-UE & $.014 * *$ & .001 & .003 & $.015^{*}$ \\
\hline$\overline{\text { TFEQ-EE }}$ & .002 & -.001 & -.002 & -.002 \\
\hline$\overline{R^{2}}$ & .44 & .12 & .09 & .22 \\
\hline Adjusted $R^{2}$ & .38 & .03 & -.001 & .14 \\
\hline$F$ & $7.597 * * *$ & 1.28 & .987 & $2.697 *$ \\
\hline
\end{tabular}

5 Note. $N=86$. Gender was dummy-coded $($ Men $=0$ and Women $=1) . \underline{\text { MBI }=\text { Maslach }}$

6 Burnout Inventory. TFEQ $=$ Three Factor Eating Questionnaire. EE $=$ Emotional

7 Exhaustion. $\mathrm{DP}=$ Depersonalisation. $\mathrm{PA}=$ Personal Accomplishment. $\mathrm{CR}=$ Cognitive

8 Restraint. $\mathrm{UE}=$ Uncontrolled Eating. $\mathrm{EE}=$ Emotional Eating.

$9 * p<.05 . * * p<.01 . * * * p .001$. 